\title{
UMEDECIMENTO DO SUBSTRATO E TEMPERATURANA GERMINAÇÃO DE SEMENTES DE ANGELIM-PEDRA (Dinizia excelsa DUCKE) ${ }^{1}$
}

\author{
VANIAPALMEIRAVARELA ${ }^{2}$, MICHELE BRAULE PINTO RAMOS ${ }^{3}$, MARIADE FÁTIMAFIGUEIREDO MELO² $^{2}$
}

RESUMO - Aágua e a temperatura estão entre os fatores essenciais para desencadear a germinação. Assim, o substrato deve estar suficientemente úmido, a fim de suprir as sementes da quantidade de água necessária para sua germinação e desenvolvimento. Por outro lado, a temperatura deve ser adequada para desencadear todas as atividades metabólicas envolvidas no processo. $\mathrm{O}$ presente trabalho foi conduzido com o objetivo de avaliar a influência de diferentes volumes de água no substrato e temperaturas na germinação das sementes de angelim-pedra (Dinizia excelsa Ducke). Antes da instalação dos testes de germinação, as sementes foram imersas em ácido sulfúrico por 20 minutos, para superação da dormência. As sementes foram colocadas para germinar em rolos de papel germitest, umedecidos com volumes $(\mathrm{mL})$ de água equivalentes a 1,5; 2,0; 2,5 e 3,0 vezes o peso do substrato sem adição posterior de água, com três folhas por rolo. Os rolos foram acondicionados em sacos de plástico e colocados em câmaras nas temperaturas constantes de 25,30 e $35^{\circ} \mathrm{C}$. Além da porcentagem de germinação, foram avaliados o índice de velocidade de germinação e os comprimentos da raiz primária e do hipocótilo. O delineamento experimental adotado foi o inteiramente casualizado, em esquema fatorial 4 × 3 , sendo empregadas 150 sementes (três repetições de 50 sementes) para cada tratamento. As combinações de volume de água no substrato e temperatura de exposição que proporcionam maiores comprimentos da raiz primária são de 1,5 e 2,0 vezes o peso do papel a $25^{\circ} \mathrm{C} ; 1,5$ vezes a $30^{\circ} \mathrm{C}$ e 3,0 vezes a $35^{\circ} \mathrm{C}$. Quanto ao comprimento do hipocótilo, as temperaturas mais altas $\left(30\right.$ e $\left.35^{\circ} \mathrm{C}\right)$ e os volumes de água acima de 2,0 vezes o peso do papel apresentam melhores resultados. Estes dados indicam que o volume de água influencia de maneira diferente, tanto o desenvolvimento da raiz primária como do hipocótilo e a temperatura influencia o desenvolvimento do hipocótilo para os maiores volumes de água no substrato.

Termos para indexação: espécie florestal, volume de água, análise de sementes.

\section{SUSTRATE MOISTURE AND TEMPERATURE IN GERMINATION OF ANGELIM PEDRA (Dinizia excelsa Ducke) SEEDS}

\begin{abstract}
Water and temperature are amongst the essential factors that set off germination. Hence, the substrate must be sufficiently moist in order to supply the seeds with the amount of water necessary for their germination and development. On the other hand, temperature has to be appropriate in order to set off all the metabolic activities involved in the process. The present study was carried out to assess the different volumes of water in the substract and temperatures on the germination of angelim pedra (Dinizia excelsa Ducke) seeds. Prior to the start of the germination tests, the seeds were treated with immersion in sulphuric acid for 10 minutes, to break dormancy. The seeds were placed to germinate in rolls of germitest paper, moistened with amounts $(\mathrm{mL})$ of water equivalent to $1.5 ; 2.0 ; 2.5$ and 3.0 times the weight of the substrate without later addition of water, with three leaves/roll. The rolls were stored in plastic bags and placed in chambers at steady temperatures of 25,30 and $35^{\circ} \mathrm{C}$. In addition to the germination percentage,
\end{abstract}

\footnotetext{
${ }^{1}$ Submetido em 07/06/2004. Aceito para publicação em 17/08/2004. Pesquisa financiada pela FAPEAM (www.fapeam.am.gov.br);

${ }^{2}$ M.Sc., Pesquisadoras, Instituto Nacional de Pesquisas da Amazônia (INPA),
}

Cx. Postal 478, CEP 69.060-001 Manaus-AM. vaniav@inpa.gov.br; ffmelo@inpa.gov.br;

${ }^{3}$ Eng. Florestal, M.Sc., INPA. mbraule@inpa.gov.br 
the germination speed, radicle length and hypocotyle, were assessed. A completely randomized design with a $4 \times 3$ factorial scheme was used with 150 seeds (three 50 seed replicates) for each treatment. The amounts of water that provided longer radicle lengths were 1.5 and 2,0 times the weight of the paper at $25^{\circ} \mathrm{C}, 1.5$ times at $30^{\circ} \mathrm{C}$ and 3.0 times at $35^{\circ} \mathrm{C}$. As to the length of the hypocotyle, the higher temperatures $\left(30\right.$ and $35^{\circ} \mathrm{C}$ ) and the amounts of water more than twice the weight of the paper presented better results. These findings showed that the water volumes influence both the root and hypocotyle development in different ways, and that temperatures only influenced the hypocotyle dvelopment.

Index terms: forest specie, water volume, seeds analysis.

\section{INTRODUÇÃO}

A espécie Dinizia excelsa Ducke é conhecida vulgarmente como angelim-pedra, pertence à família LeguminosaeMimosoideae e ocorre com freqüência na Amazônia, nos Estados do Amazonas, Pará, Rondônia e Roraima. Sua madeira é empregada para fabricação de chapas decorativas, dormentes, construção civil e naval, macetas, marcenaria, carpintaria, cepos de bigornas e açougue, calçamento de ruas e implementos agrícolas, sendo ainda resistente ao ataque de fungos e termitas (Loureiro et al., 1979).

O conhecimento das condições adequadas para a germinação de sementes de uma espécie é de fundamental importância, principalmente pelas respostas diferenciadas que podem apresentar devido a diversos fatores como dormência, condições ambientais: água, luz, temperatura, oxigênio e ocorrência de agentes patogênicos associados ao tipo de substrato para sua germinação (Ramos e Bianchetti, 1984; Popinigis, 1985; Brasil, 1992; Carvalho e Nakagawa, 2000).

A disponibilidade de água é um dos fatores essenciais para desencadear a germinação. Durante esse processo, a absorção de água promove o amolecimento do tegumento, o aumento do embrião e dos tecidos de reserva, favorecendo a ruptura do tegumento, a difusão gasosa e a emergência da raiz primária. Proporciona, ainda, a diluição do protoplasma, permitindo a difusão de hormônios e, conseqüentemente, ativação de sistemas enzimáticos e, com isso, desenvolvemse a digestão, a translocação e a assimilação das reservas, resultando no crescimento do embrião (Marcos Filho, 1986).

Nos testes de germinação realizados em laboratório, o substrato deve permanecer uniformemente úmido, a fim de suprir as sementes da quantidade de água necessária para sua germinação e desenvolvimento. Deve-se salientar que, em geral, o excesso de umidade provoca um decréscimo na germinação, visto que dificulta a respiração e reduz todo o processo metabólico resultante, além de aumentar a incidência de fungos, levando à redução na viabilidade (Figliolia et al., 1993).

Os estudos de germinação, relacionados ao nível de umidade do substrato, são pioneiros na tecnologia de sementes de espécies florestais da Amazônia, contribuindo para auxiliar na condução dos testes de germinação e redução da discrepância entre os resultados obtidos em laboratório. Pesquisas sobre as exigências de água em sementes de espécies agrícolas realizados por Phaneendranath (1980), Tanaka et al., (1991) e Novembre e Marcos Filho (1999) têm mostrado resultados consistentes, obtidos quando a umidade é controlada através de cálculo baseado na relação volume de água e peso do substrato do papel sem hidratação posterior.

A temperatura apresenta grande influência tanto na porcentagem como na velocidade de germinação das sementes, estando relacionada às reações bioquímicas que regulam o metabolismo necessário para iniciar o processo de germinação (Carvalho e Nakagawa, 2000).

As sementes apresentam comportamento variável quanto à temperatura, não havendo uma temperatura ótima e uniforme para todas as espécies, sendo considerada ótima a temperatura na qual a semente expressa seu potencial máximo de germinação e as temperaturas máxima e mínima os pontos críticos onde acima e abaixo das quais, respectivamente, não ocorre germinação (Popinigis, 1985; Mayer e PoljakoffMayber, 1989).

A temperatura ótima para a germinação da maioria das espécies está entre 20 a $30^{\circ} \mathrm{C}$ e a máxima entre 35 e $40^{\circ} \mathrm{C}$ (Marcos Filho, 1986). A faixa de 20 a $30^{\circ} \mathrm{C}$ também foi considerada, por Borges e Rena (1993), como a mais adequada para a germinação de grande número de espécies florestais subtropicais e tropicais. 
Para as sementes de espécies florestais, muitos estudos têm sido realizados para definir as temperaturas usadas nos testes de germinação, conforme experimentos com sementes de Cedrela odorata L. (Andrade e Pereira, 1994); Maquira sclerophylla (Ducke) C. C. Berg (Miranda e Ferraz, 1999); Ceiba pentandra (L) Gaertn (Varela et al., 1999); Ochroma pyramidale (Cav. Ex. Lamb.) Urban e Enterolobium schomburgkii Benth. (Souza et al., 2000). Entretanto, os estudos sobre a influência da quantidade de água no substrato e da temperatura sobre a germinação das sementes de angelimpedra não estão disponíveis na literatura. Diante da carência de informações sobre conhecimentos tecnológicos das sementes desta espécie, o presente trabalho foi conduzido para avaliar a germinação das sementes de $D$. excelsa em função de diferentes volumes de água e temperaturas.

\section{MATERIALE MÉTODOS}

Os frutos de $D$. excelsa utilizados nesse estudo foram coletados de uma árvore matriz localizada no Campus do Instituto Nacional de Pesquisa da Amazônia - INPA. Após a coleta dos frutos no chão, procedeu-se a extração das sementes.

Antes da instalação dos testes de germinação, as sementes foram imersas em ácido sulfúrico por 20 minutos, para superar a dormência, conforme recomendação de Vastano Jr. et al., (1983).

As sementes foram submetidas ao teste de germinação em rolos de papel germitest, umedecidos com volumes $(\mathrm{mL})$ de água equivalentes a 1,5; 2,0; 2,5 e 3,0 vezes o peso do substrato sem adição posterior de água, com três folhas por rolo. Os rolos foram acondicionados em sacos de plástico com $0,04 \mathrm{~mm}$ de espessura, com a finalidade de evitar a perda de umidade, e colocados em câmara com fotoperíodo de 12 horas, providas de lâmpadas fluorescentes de luz branca fria e fluxo luminoso de $10 \mathrm{mmol} . \mathrm{m}^{-2} . \mathrm{s}^{-1}$ de radiação PAR (radiação fotossinteticamente ativa). Foram testadas as temperaturas constantes de 25 , 30 e $35^{\circ} \mathrm{C}$.

As avaliações foram efetuadas aos sete e quatorze dias após a instalação do teste, determinando-se as porcentagens de germinação. Foi calculado o índice de velocidade de germinação, considerando-se a primeira e última contagens, conforme equação proposta por Maguire (1962). Foram ainda avaliados o comprimento da raiz primária e do hipocótilo, com o auxílio de régua milimetrada, tomando-se dez plântulas por repetição, para cada tratamento.

O delineamento experimental adotado foi o inteiramente casualizado, em esquema fatorial 4x3, sendo empregadas 150 sementes (três repetições de 50 sementes) para cada tratamento.

Os dados em porcentagens foram transformados em arc $\operatorname{sen} \sqrt{X / 100}$, porém na tabela foram apresentados os dados originais. Para os dados de comprimento da raiz primária e do hipocótilo, foi realizada análise de regressão em função da quantidade de água no substrato.

\section{RESULTADOS E DISCUSSÃO}

Na Tabela 1, encontram-se as médias das porcentagens de germinação, obtidas de acordo com as temperaturas e quantidades de água no substrato para as sementes de $D$. excelsa. Os resultados obtidos com as sementes submetidas aos volumes de água equivalentes a 1,5; 2,0; 2,5 e 3,0 vezes o peso do papel e as temperaturas de 25,30 e $35^{\circ} \mathrm{C}$ indicaram que as interações entre esses fatores não exerceram influência sobre as porcentagens de germinação das sementes de $D$. excelsa. As temperaturas testadas também não afetaram as porcentagens de germinação das sementes. Foram obtidas altas taxas de germinação nas temperaturas de 25,30 e $35^{\circ} \mathrm{C}$, com 91, 89 e 87\%, respectivamente. Para as sementes de Tabebuia capitata, Castro (2003) verificou que as temperaturas de 30 e $35^{\circ} \mathrm{C}$ resultaram nas maiores porcentagens de germinação, tanto para protrusão da raiz primária quanto para formação de plântulas normais. Esses dados estão de acordo com os apresentados por Borges e Rena (1993), onde sementes de grande número de espécies florestais subtropicais e tropicais mostram seu potencial máximo de germinação na faixa de temperatura entre 20 e $30^{\circ} \mathrm{C}$.

Triplaris surinamensis e Dipteryx alata, espécies nativas da floresta amazônica, também apresentaram melhores taxas de germinação das sementes nas temperaturas de $25^{\circ} \mathrm{C}$ e entre

TABELA1. Médias das porcentagens de germinação de sementes de $D$. excelsa obtidas em diferentes temperaturas $\left({ }^{\circ} \mathrm{C}\right)$ e quantidades de água no substrato (em função do peso do substrato).

\begin{tabular}{ccccc}
\hline \multirow{2}{*}{ Quantidade de água } & \multicolumn{3}{c}{ Temperatura } & \multirow{2}{*}{ Médias } \\
\cline { 2 - 4 } & 25 & 30 & 35 & \\
\hline 1,5 & 95 & 91 & 79 & 88 \\
2,0 & 90 & 93 & 93 & 92 \\
2,5 & 87 & 86 & 89 & 87 \\
3,0 & 92 & 89 & 85 & 88 \\
\hline Médias & 91 & 89 & 87 & \\
\hline
\end{tabular}

$\mathrm{CV}=8,3 \%$ ns - não significativo para temperatura, quantidade de água e interação. 
25 e $30^{\circ} \mathrm{C}$, respectivamente (Carneiro et al., 1997).

Para as sementes de Leandra breviflora, Tibouchina benthamiana e T. moricandiana, espécie da mata Atlântica, as temperaturas de 20,25 e $30^{\circ} \mathrm{C}$ foram as melhores para emissão da raiz primária (Andrade, 1995).

Os resultados da porcentagem de germinação (Tabela 1) não evidenciaram diferença significativamente entre os tratamentos, indicando que as quantidades de água no substrato não exerceram influência sobre as médias de germinação das sementes de $D$. excelsa.

Informações relacionadas à velocidade de hidratação mostram que este fator está ligado à disponibilidade hídrica, potencial mátrico do substrato, potencial osmótico da solução que umedece o substrato, temperatura e características intrínsecas da semente (Vertucci e Leopold, 1983; Popinigis, 1995).

No levantamento bibliográfico realizado não foram encontradas informações sobre umedecimento do substrato em sementes de espécies florestais; desta forma, a discussão se limitar-se-á à comparação dos resultados obtidos com os observados para as sementes de interesse agrícola. Para sementes de amendoim, Tanaka et al. (1991) observaram que as quantidades de água no substrato de 1,5; 2,0; 2,5 e 3,0 não apresentaram influência, sobre a taxa de germinação. Entretanto, o umedecimento do substrato com volume de água igual a 3,0 vezes o peso do papel mostrou ser desfavorável à germinação de sementes de maxixe (Gentil e Torres, 2001). Resultados similares foram obtidos quando o substrato foi umedecido com quantidade de água equivalente a 3,0 vezes o seu peso, conforme experimentos realizados com sementes de pepino, melão e melancia por Menezes et al. (1993).

Gentil e Torres (2001) comprovaram que o umedecimento do substrato nos volumes de água equivalentes a 1,0; 1,5; 2,0; 2,5 vezes o peso do papel não prejudicou a germinação de sementes de maxixe. Segundo Vicente et al. (1969), a germinação mais favorável pode não ser induzida por somente um volume de água, mas por diversos volumes que ocupam uma faixa de amplitude específica, conforme a espécie. Para as sementes da espécie em estudo, os volumes de água na faixa de 1,5; 2,0; 2,5 e 3,0 foram favoráveis para a germinação das sementes e não causaram prejuízos ao processo germinativo. Esses resultados, indicam que as sementes de D. excelsa toleram uma faixa de amplitude de volume de água maior que as sementes de espécies agrícolas mencionadas anteriormente.

Os resultados do índice de velocidade de germinação, conforme mostra Tabela 2, não evidenciaram diferença entre as temperaturas, as quantidades de água no substrato e a interação entre esses fatores, indicando que esta variável não foi influenciada pelos tratamentos testados. Estudando sementes de porongo (Largenaria siceraria), Bisognin et al. (1991), observaram menor velocidade de germinação quando utilizaram a proporção de água equivalente a 3,0 vezes o peso do substrato. Da mesma forma que ocorreu com as porcentagens de germinação, as sementes de angelim-pedra possivelmente toleram maior amplitude de faixa de volume de água sem influenciar a velocidade do processo.

O desempenho do comprimento da raiz primária $(\mathrm{cm})$ de $D$. excelsa em função do umedecimento do substrato, encontra-se na Figura 1. Nas temperaturas de 25 e $30^{\circ} \mathrm{C}$, observou-se que houve redução no comprimento da raiz devido ao aumento da quantidade de água no substrato. Para a temperatura de $25^{\circ} \mathrm{C}$, os melhores resultados foram obtidos com as quantidades de água de 1,5 e 2,0 vezes o peso do

TABELA2. Médias do índice de velocidade de germinação (IVG) das sementes de $D$. excelsa, obtidas em diferentes temperaturas $\left({ }^{\circ} \mathrm{C}\right)$ e quantidades de água no substrato (em função do peso do substrato).

\begin{tabular}{ccccc}
\hline \multirow{2}{*}{ Quantidade de água } & \multicolumn{3}{c}{ Temperatura $\left({ }^{\circ} \mathrm{C}\right)$} & \multirow{2}{*}{ Médias } \\
\cline { 2 - 4 } & 25 & 30 & 35 & \\
\hline 1,5 & 11,0 & 10,9 & 9,1 & 10,3 \\
2,0 & 10,9 & 11,2 & 10,2 & 10,8 \\
2,5 & 10,5 & 10,0 & 10,0 & 10,2 \\
3,0 & 10,3 & 10,8 & 9,4 & 10,2 \\
\hline Médias & 10,7 & 10,7 & 9,7 & \\
\hline
\end{tabular}

$\mathrm{CV}=10,3 \%$. ns - não significativo para temperatura, quantidade de água e interação.

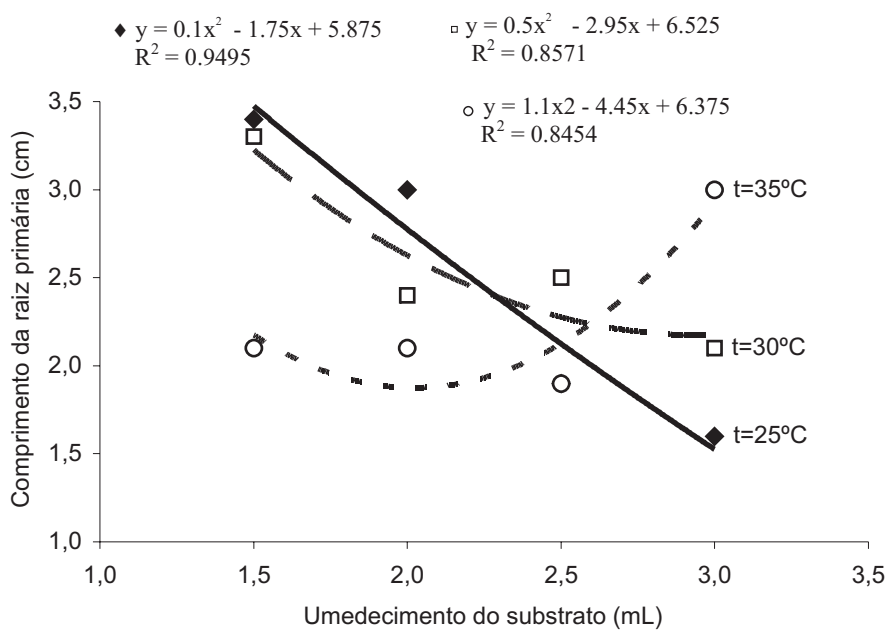

FIGURA 1. Comprimento da raiz primária $(\mathrm{cm})$ de sementes de D. excelsa, germinadas em diferentes temperaturas (t) e quantidades de água no substrato. 
substrato, com 3,4 e 3,0cm de comprimento, respectivamente. Para a temperatura de $30^{\circ} \mathrm{C}$, o melhor resultado foi obtido com o volume de água de 1,5 vezes o peso do substrato, com $3,3 \mathrm{~cm}$ de comprimento. Na temperatura de $35^{\circ} \mathrm{C}$, o comprimento da raiz primária foi favorecido pelo aumento da quantidade de água no substrato, sendo que os melhores resultados (3,0 cm de comprimento) foram observados com 3,0 vezes o peso do papel.

Na Figura 2, encontram-se os resultados do comprimento do hipocótilo de $D$. excelsa, germinadas em diferentes temperaturas e quantidades de água no substrato. Para a temperatura de $25^{\circ} \mathrm{C}$, observa-se que ocorre similaridade de comprimento do hipocótilo entre os volumes de água testados. Nesta temperatura, os resultados do crescimento do hipocótilo foram inferiores quando comparados às outras temperaturas. $\mathrm{Na}$ temperatura de $30^{\circ} \mathrm{C}$, os melhores resultados foram obtidos com as quantidades de água de 2,0, 2,5 e 3,0 vezes o peso do papel, com 4,8, 5,2 e 5,0 cm de comprimento do hipocótilo, respectivamente. Para a temperatura de $35^{\circ} \mathrm{C}$, observou-se aumento significativo no comprimento do hipocótilo em função do aumento da quantidade de água no substrato. Nesta temperatura, os maiores comprimentos do hipocótilo foram alcançados a 2,0, 2,5 e 3,0 vezes o peso do substrato, com 4,6, 5,5 e 5,5cm, respectivamente.

Analisando-se simultaneamente as Figuras 1 e 2, observase que o melhor resultado foi obtido na temperatura de $35^{\circ} \mathrm{C}$ com a quantidade de água de 3,0 vezes o peso do papel, proporcionando melhor desenvolvimento das plântulas.

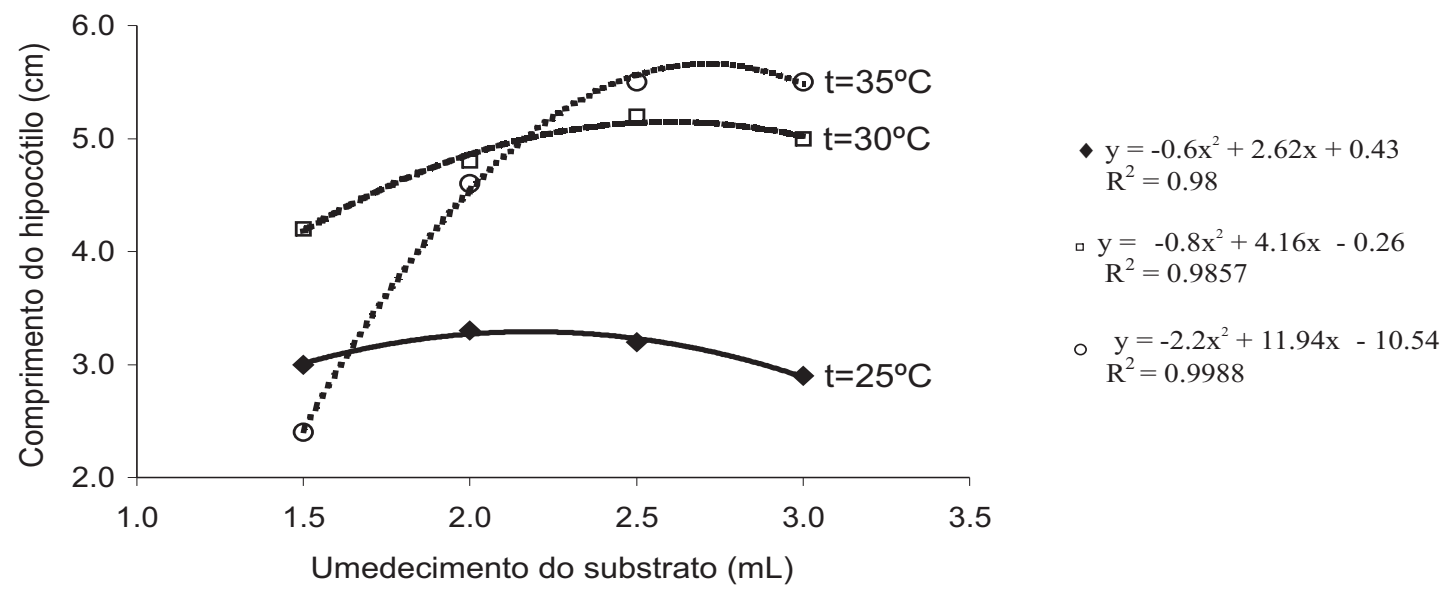

FIGURA 2. Comprimento do hipocótilo (cm) de sementes de $D$. excelsa, germinadas em diferentes temperaturas (t) e quantidades de água no substrato.

\section{CONCLUSÕES}

Os volumes de água no substrato influenciam de maneira diferente tanto o desenvolvimento da raiz primária como do hipocótilo e as temperaturas de 30 e $35^{\circ} \mathrm{C}$ favorecem o desenvolvimento do hipocótilo para os maiores volumes de água no substrato.

Os volumes de água que proporcionam maiores comprimentos da raiz primária são 1,5 e 2,0 vezes o peso do papel a $25^{\circ} \mathrm{C} ; 1,5$ vezes a $30^{\circ} \mathrm{C}$ e 3,0 vezes a $35^{\circ} \mathrm{C}$.

Quanto ao comprimento do hipocótilo, as temperaturas mais altas (30 e $35^{\circ} \mathrm{C}$ ) e os volumes de água acima de 2,0 vezes o peso do papel apresentam melhores resultados.
O desenvolvimento da raiz e do hipocótilo é favorecido simultaneamente a $35^{\circ} \mathrm{C}$ com a quantidade de água de 3,0 vezes o peso do papel.

\section{REFERÊNCIAS}

ANDRADE, A.C.S. Efeito da luz e temperatura na germinação de Leandra breviflora Cogn., Tibouchina benthamiana Cogn., Tibouchina glandiflora Cogn., e Tibouchina moricandiana (DC.) Boill (Melastomataceae). Revista Brasileira de Sementes, Brasília, v. 20, n.2, p.29-35, 1995.

ANDRADE, A.C.S.; PEREIRA, T.S. Efeito do substrato e da temperatura na germinação e no vigor de sementes de cedro Cedrela odorata L. (Meliaceae). Revista Brasileira de Sementes, Brasília, v.16, n.1, p.34-40, 1994. 
BISOGNIN, D.A.; IRIGON, D.L.; MARTINAZZO, A.A. Teste de germinação em porongo - Lagenaria siceraria (Mol.) Standi. Ciência Rural, Santa Maria, v.21, n.2, p.159-167, 1991.

BORGES, E.E.I.; RENA, A.B. Germinação de sementes. In: AGUIAR, I.B.; PINÃ-RODRIGUES, F.C.M.; FIGLIOLIA, M.B. (Ed): Sementes florestais tropicais. Brasília: ABRATES, 1993. p.83136.

BRASIL. Ministério da Agricultura e Reforma Agrária. Regras para análise de sementes. Brasília: SNDA/DNDV/CLAV, 1992. 365p.

CARNEIRO, N.B.; FERRAZ, I.D.K.; VARELA, V.P. Efeito da temperatura sobre a germinação de sementes de Triplaris surinamensis Cham e Dipteryx alata Vog. In: JORNADA DE INICIAÇÃO CIENTÍFICA DO INPA, 6, 1997. Manaus, Anais... Manaus: INPA, 1997. v.1, p. 219-222.

CARVALHO, N.M.; NAKAGAWA, J. Semente: ciência, tecnologia e produção. 4 ed. Jaboticabal: FUNEP, 2000. 588p.

CASTRO, M.N. Influência de diferentes temperaturas na germinação de sementes de ipê (Tabebuia capitata (Bur. \& K. Schum.) Sandw. Instituto de Tecnologia da Amazônia, 2003. 24p. Monografia.

FIGLIOLIA, M.B.; OLIVEIRA, E.C.; PINÃ-RODRIGUES, F.C.M. Análise de semente. In: AGUIAR, J.B. ; PINÃ-RODRIGUES, F.C.M.; FIGLIOLIA, M.B. (Ed.) Sementes florestais tropicais. Brasília: ABRATES, 1993. p.173-174.

GENTIL, P.F.; TORRES, S.B. Umedecimento do substrato e germinação de sementes de maxixe (Cucumis anguria L.). Revista Brasileira de Sementes, Brasília, v.23, n.2, p.113-116, 2001.

LOUREIRO, A.A.; SILVA, M.F.; ALENCAR, J.C. Essências madeireiras da Amazônia. Manaus: INPA / SUFRAMA, 1979, v. 1.245p.

MAGUIRE, J.O. Speed of germination and in selection and evaluation for seedling emergence and vigor. Crop Science, Madison, v. 2, n.2, p.176-177, 1962.

MARCOS FILHO, J. Germinação de sementes. In: SEMANA DE ATUALIZAÇÃO EM SEMENTES, 1. Campinas: Fundação Cargill, 1986. p.11-39.

MAYER, A.M.; POLJAKOFF-MAYBER, A. The germination of seeds. Oxford: Pergamon Press,1989. 270p.

MENEZES, N.L.; SILVEIRA, T.L.D.; STORCK, L. Efeito do nível de umedecimento do substrato sobre a germinação de cucurbitáceas. Ciência Rural, Santa Maria, v.23, n.2, p.157-160, 1993.
MIRANDA, P.R.M.; FERRAZ, I.D.K. Efeito da temperatura na germinação de sementes e morfologia da plântula de Maquira sclerophylla (Ducke) C. C. Berg. Revista Brasileira de Botânica, São Paulo, v.22, n.2, p.303-307, 1999. Suplemento

NOVEMBRE, A.D.L.C.; MARCOS FILHO, J. Estudo da metodologia para condução do teste de germinação em sementes de algodão deslintadas mecanicamente. Revista Brasileira de Sementes, Brasília, v.21, n.2, p.187-193, 1999.

POPINIGIS, F. Fisiologia da semente. Brasília: AGIPLAN, 1985. 289p.

PHANEENDRANATH, B.R. Influence of amount of water in the paper towel on standard germination tests. Journal of Seed Technology, Lansing, v.5, n.2, p.82-87, 1980.

RAMOS, A.; BIANCHETTI, A. Influência da temperatura e do substrato na germinação de sementes florestais. In: SIMPÓSIO INTERNACIONAL SOBRE PRODUÇÃO E QUALIDADE DE SEMENTES FLORESTAIS, Curitiba, 1984. Anais... Curitiba: UFPR, 1984. p.252-275.

SOUZA, M.A.S.; VARELA, V.P.; FERRAZ, I.D.K. Influência de diferentes temperaturas na germinação de sementes de espécies florestais da Amazônia. I.Pau-de-balsa (Ochroma pyramidale (Lav Ex. Lam. ) Urban). II. Faveira orelha de macaco (Enterolobium schomburgkii Benth) . In: JORNADA DE INICIAÇÃO CIENTÍFICA DO INPA, 9, 2000. Manaus, Anais... Manaus: INPA, v.1, p.255-258, 2000.

TANAKA, M.A S.; MARIANO, M.I.A.; LEÃO, N.V.M. Influência da quantidade de água, no substrato sobre a germinação de sementes de amendoim. Revista Brasileira de Sementes, Brasília, v.13, n. 1, p. 73-76, 1991.

VARELA, V.P.; FERRAZ, I.D.K.; CARNEIRO , N.B. Efeito da temperatura na germinação de sementes de sumaúma (Ceiba pentandra L. Gaertn - Bombacaceae). Revista Brasileira de Sementes, Brasília, v. 21, n.2, p.170-174, 1999.

VASTANO JR, B.; BARBOSA, A.P.; GONÇALVES, A. N. Tratamentos pré-germinativo de sementes de espécies florestais amazônicas. I- Angelim-pedra (Dinizia excelsa Ducke) Leguminosae, Mimosoideae. Acta Amazonica, Manaus, v.13, n.2, p.415-419, 1983.

VERTUCCI, C.W.; LEOPOLD, A.C. Dynamics of imbibition of soybean embryos. Plant Physiology, v.72, p.190-193, 1983.

VICENTE, M., NORONHA, A.; SILBERSCHMIDT, K. Substrate moisture levels for germination testing of some agricultural seeds. Anais da Academia Brasileira de Ciências, Rio de Janeiro, v.41, n.4, p.633-639, 1969. 